\title{
HERSTELLINGEN AAN DE SINT-ANTONIUSKERK TE BLANKENBERGE TEN TIJDE VAN PASTOOR ROYER (1740-1766)
}

De Sint-Antoniuskerk te Blankenberge, in 1937 door de Commissie van monumenten geklasseerd, paart aan een rijk kunstpatrimonium een interessante en merkwaardige geschiedenis ${ }^{1}$. Alleen reeds onder het herderschap van Julien Joseph Royer, pastoor te Blankenberge van 1740 tot 1766 , gebeurden belangrijke realisaties en restauraties. Financieel kon de pastoor daarbij rekenen op de milde steun van het stadsmagistraat en niet in het minst op deze van de vissersnering. De merkwaardige groei van het visserijbedrijf te Blankenberge tijdens de Oostenrijkse periode, zal daar zeker niet vreemd aan geweest zijn. Immers gans de $18 \mathrm{e}$ eeuw door is er een konstante toename van het aantal eenheden in de vissersvloot ${ }^{2}$.

$\begin{array}{llll}1720 & 32 \text { schuiten } & 1760 & 52 \text { schuiten } \\ 1725 & 32 \text { schuiten } & 1765 & 53 \text { schuiten } \\ 1730 & 31 \text { schuiten } & 1770 & 61 \text { schuiten } \\ 1735 & 38 \text { schuiten } & 1775 & 68 \text { schuiten } \\ 1740 & 38 \text { schuiten } & 1780 & 72 \text { schuiten } \\ 1745 & 41 \text { schuiten } & 1785 & - \text { schuiten } \\ 1750 & 50 \text { schuiten } & 1790 & 77 \text { schuiten } \\ 1755 & 49 \text { schuiten } & & \end{array}$

Een eerste aanwinst onder pastoor Royer waren drie nieuwe klokken. In 1754 ging het Blankenbergs stadsmagistraat akkoord de drie bestaande klokken te vervangen ${ }^{3}$ en voor $2 / 3$ in de kostprijs van drie nieuwe tussen te komen ${ }^{4}$. De Brugse klokgieter Georges Dumery, die reeds in 1751 aan de stad een klok had geleverd «tot den heurslagh

1. Voor de geschiedenis van de Sint-Antoniuskerk moeten we verwijzen naar onze studie over de kerk in voorbereiding. 178.

2. R.A.B., Oud archief Blankenberge, Rekeningen, nrs. 118 tot

3. Ibidem, idem, nr. 17, fol. 29 en 29 v. Aanwinsten nr. 2579, fol. 108: «Betaelt aen Laureyns Maes timmerman 3 p. 11 sch. 11 gr. over aerbeytsloon soo over hem als sijnen knecht int af ende ophangen van alle drije de klocken ...».

4. Ibidem, idem, nr. 150, fol. 21: «... dat de kercke daer over moeste draegen het gerechte derde ende dese stadt twee derden». 
binnen der stadthuijse» ${ }^{5}$, kreeg de opdracht. Als voorwaarden stelde het magistraat «... als dat den voorseyden D'Em. mery de selve sal leveren van goeden toon .... voorts sal op de selve moeten ghestelt worden het waepen van de stadt, de naem vanden heer pastor ende van burghmeesters ende schepenen».

Twee der oude klokken werden in het atelier van Dumery te Brugge hersmolten, terwijl de kleinste in de kerk bleef tot bij de overname van de nieuwe klokken in juni $1754^{\circ}$. Deze klokken heeft men tot de sluiting van de kerk in 1889 gebruikt; de twee kleinste werden toen hergoten en de grootste bracht men over naar de nieuwe Sint-Rochuskerk. Er stond inderdaad volgend opschrift op ${ }^{7}$ :

D'Heer en meester Julianus Josephus Royer pastoor de weth der stede ende port van Blankenberghe bailliu d'heer F.J. Vander Beke

Burghmeester d'heer Jan Vander Beke burghmeester van den commune d'heer J. Gouverneur schepenen d'heer C. E. Mallet o et a d'heer Jacob van Mirop kerckmeester d'heer J. Janssens d'heer J.A. De Buisson d'heer J.L. De Vos d'heer P. Bousse d'heer J. Scheurs d'heer P. Reynaert d'heer Joannes Van Windekens tresorier ende kerckmeester d'heer ende meester A.C.J. Walwein pentionaris ende greffier

Georgius Du Mery me fecit Brugis anno 1754

Deze klok, samen met de andere, hebben de Duitsers in 1917 en opnieuw in 1943 opgevorderd. Hergoten in 1949, vertoonde zij in 1966 een barst aan de rand zodat hetzelfde jaar, in opdracht van de kerkfabriek, door de firma F. Sergeys uit Leuven een nieuwe klok gegoten werd. Daarop is inderdaad de ganse historiek van de klok af te lezen ${ }^{8}$.

Vervolgens kreeg het interieur een grondige beurt. In 1761 werd een nieuwe vloer van «blauwe baseecksche teghels» gelegd ${ }^{9}$ en met toestemming van de heer landsdeken verplaatste men de zitsels uit de middenbeuk naar de zij-

5. Ibidem, idem, nr. 16bis. Over G. Dumery zie Ann. Soc. Em. Brugge, VII (1845), blz. 235 en vlg.

6. Ibidem, idem, nr. 17 , fol. $30 \mathrm{v}$ en $34 \mathrm{v}$.

7. L. Legougeux, Blankenberghe. Histoire et Souvenirs, Blankenberge, 1905, blz. 263-264.

8. Kerkfabriek Sint-Rochus, Opschriften van de klokken: «Primum a Georgio de Mery anno MDCCLIV factam, bis grassante 


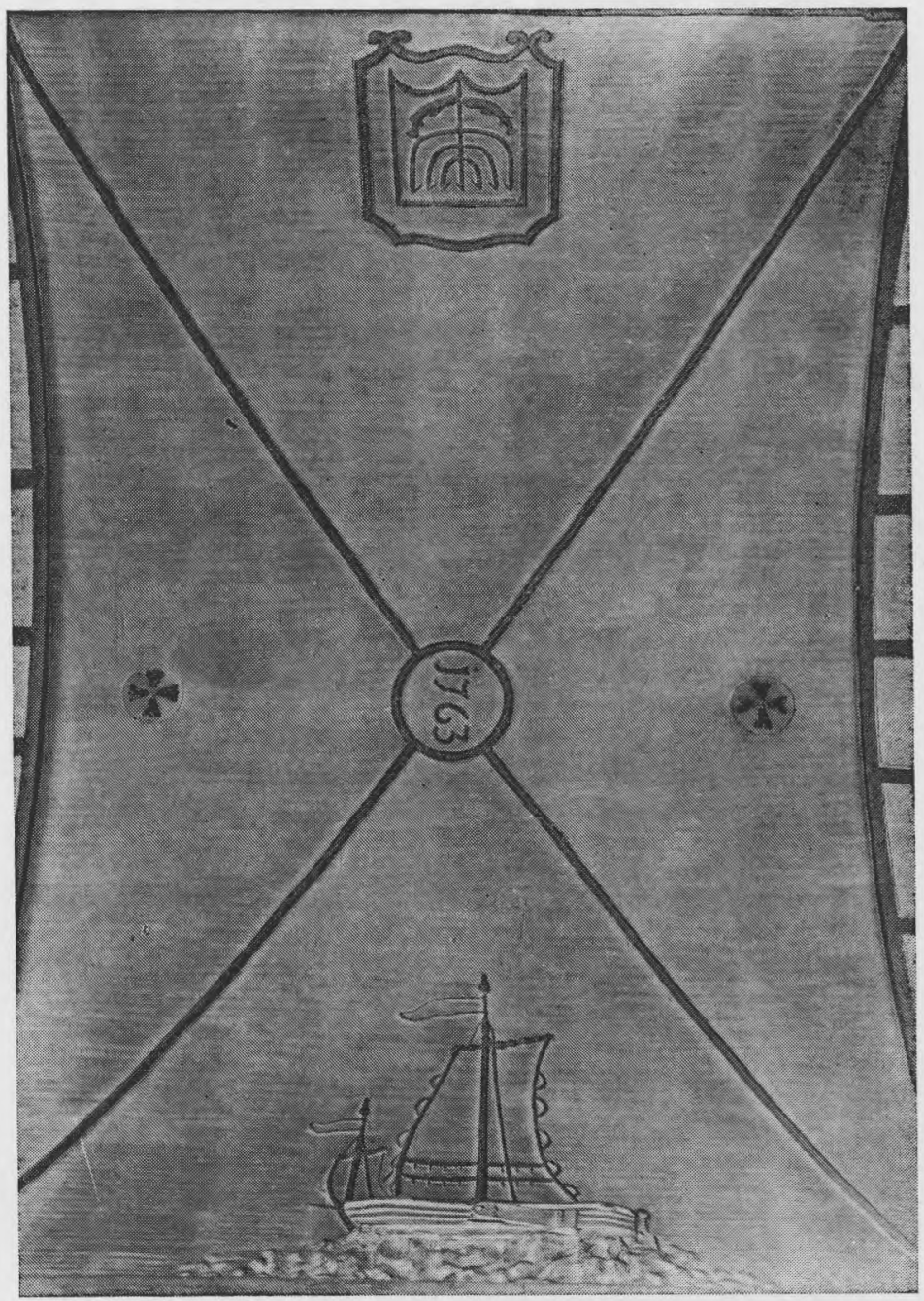


beuken ${ }^{10}$. In de Sint-Antoniusbeuk kwam het zitsel van deken en eed der visserij, dat van de Sint-Antoniusmeesters en ook het vernieuwde zitsel der kerkmeesters ${ }^{11}$. In de O.-L.-Vrouwbeuk plaatste men «het ghonne van O.L.Vrauw, vande paters bightstoel ... voorwaerts tot aende autaer ende het ghonne van het Heyligh Cruys ... aghterwaerts vande paters bighstoel».

Eveneens had men beslist een nieuw orgel te laten bouwen ter vervanging van dat welke de stad in 1712-1713 aan de Sint-Trudoabdij te Brugge had gekocht ${ }^{12}$. Daartoe was door de Blankenbergse vissersnering een milde gift beloofd. Maar eenmaal projekt en tekening van het orgel klaar, bleek het noodzakelijk dat de stad eveneens haar duit in het zakje deed «ghesien het plan van diere met de apparenten oncost ... merckelick sal commen te excederen de jonste vande visscherije en het ghonne soude connen commen uyt de jonste vande borgherije...». Immers ook doksaal en trap van 1712 moesten volledig vernieuwd worden om het nieuwe orgel te kunnen plaatsen ${ }^{13}$.

A.J. Berger, meester orgelbouwer, kreeg op 17 november 1762 het werk toegewezen. Andries Jacobus Berger behoorde tot het 18e-eeuws geslacht van orgelmakers uit Brugge. Naast onderhoud en herstellingswerk aan diverse orgels zijn van hem o.m. gekend de nieuwe instrumenten in de Blindekenskapel, de Sint-Gilliskerk en het Begijnhof te Brugge ${ }^{14}$.

bello anno MCMXVII et MCMXXXXIII ereptam me fudit anno MCMXXXXIX G. Slegers-Causard me denique novam funderunt anno MCMLXVI Fr. Sergeys et filius eius Lovanii in honorem Sancti Josephi ....».

9. R.A.B., Aanwinsten nr. 2581, fol. 95-95v. Basècle, gemeente in de provincie Henegouwen, gekend voor steengroeven.

10. Ibidem, Oud archief Blankenberge, nr. 17, fol. 294 en fol. $300 \mathrm{v}-301$.

11. Ibidem, Aanwinsten nr. 2581, fol. 98: «Voorts betaelt aen Pieter de Roo meester schrijnwerker binnen Brugghe de somme van 8 p. gr. over het maecken ende leveren van het kerckmeesters zitsel in de kercke deser stede».

12. Ibidem, Oud archief Blankenberge, nr. 144, fol. 46v-47: «Betaelt aen Pieter Scharre 25 p. over Mevr. d'abdesse van het clooster van St. Trudo binnen Brugge soo veele dese stadt aen het selve clooster schuldigh was over coop van een orgel de gonne inde kercke deser stede staet». In 1521 was een nieuw orgel geplaatst geworden door Charles Waeghers, zie: F. François, Brugse orgelmakers, in Biekorf, IL (1948), blz. 155.

13. Ibidem, idem, nr. 17, fol. 305-306v. 
Het nieuwe orgel voor de Sint-Antoniuskerk zou aan de volgende voorwaarden geleverd worden ${ }^{15}$ :

Voor eersts, sal den aennemer moeten leveren een nieuw secreet van uijtghelesen waegheschot, van 48 canaelen, met sijn gheleedt, oock twee nieuwe clauwieren van ghelicke 48 voeten tousse ider, de toussen van wit suijver been, ende de diesen van bruijn hebben haut, een clauwier sal moeten dienen voor d'orghel, tweede dito voor een echo van drije octaven sal een tweede cornet wesen, voorts drije blaesebalgen volghens den heisch van dit werck.

nr. 1 devanture vier voet open, ontrent ses voeten in parade van stoffe gemengelt loot en tin, verciert met witte foelie.

2 bourdon aght voet sprekende ghestopt, d'eerste octave van waegheschot ende de volgende pijpen van stoffe als boven.

3 cornet van vijf pijpen op ieder tousse beginnende op de laré int midden van t'clauwier stoffe.

4 fluijte sprekende vier voet ghestopt van stoffe.

5 doublette twee voet van stoffe.

6 nazaert ofte quinte fluijte van stoffe.

7 quart nazaert van stoffe.

8 tierce van stoffe.

9 fourniture à drije pijpen op ieder tousse van stoffe.

10 cijmbal à twee pijpen op ieder tousse van stoffe.

11 trompet van engels tin sprekende 8 voet gesneden op t'secreet den bas van dé superius.

12 clairon oock engels tin sprekende vier voet oock ghesneden.

13 een trambland d'oux 14 nagtegael en ventijl.

Voorts een echo cornet sprekende drije octaven op tweede clauwier van vier pijpen op een tousse van stoffe.

Desen orghel voltrocken wesende de twee eerste jaeren aghter een volghende goet te hauden door den aennemer sonder vergelt.

Voorts eene nieuwe waegheschotte orghel casse, met drije vaesen, volgens de teeckeninghe sonder speck ende dat alle voor eene somme van veerthien hondert vijftigh guldens vlams courant gelt te weten twee hondert guldens vier maen-

14. F. François, o.c., blz. 160-161.

15. R.A.B., Oud archief Blankenberge, nr. 17, fol. 339v en vlg. 
den naer het sluijten van het accord ende twee hondert guldens vier maenden daernaer ende het resterende van duijsent en vijftigh guldens, als den orghel geheel gedaen ende overgenomen sal sijn.

Voorts een eerelick defroij ten tijde van het opstellen oft monteren van het werck, ontrent ses weken, met ofte ghetween te verleenen binnen desen steden huijse, als oock het transport vande orghel ende casse, ten coste van d'heeren aenbesteeders.

Zoals beloofd, staken de 53 eenheden van de Blankenbergse vissersvloot tijdens de eerstvolgende maanden ${ }^{16}$ in zee om de opbrengst van een reis integraal af te dragen tot het bekostigen van het orgel. Die opbrengst beliep $93 \mathrm{p}$. 14 sch. 2 gr. ${ }^{17}$, t.t.z. nog niet de helft van de totale kostprijs van het orgel, zodat de subsidie van het magistraat en de «jonste» van de bevolking een niet te onderschatten aandeel geweest zijn!

Uit de beschrijving blijkt dat dit orgel voor de Sint-Antoniuskerk van het klassieke «Berger-type» was, namelijk een goed bezet vier voetsorgel. Enkele bijzonderheden echter maakten dit orgel tot een uniek Bergerinstrument. Volgens J. Marichal ${ }^{18}$ is dit het enige éénklaviersorgel van Andries Jacobus Berger dat naast de gebruikelijke cornet vijf rangen nog een echo-cornet vier rangen bezat. Dit echowerk werd bespeeld vanaf een daartoe speciaal toegevoegd tweede manuaal van drie oktaven. Naast de aanwezigheid van de echo-cornet valt het ook op dat de clairon vier voet zowel in de baskant als in de diskant kon gespeeld worden, hetgeen eerder zeldzaam was op een klein Berger-orgel (meestal disposeerde hij clairon vier baskromhoorn acht voet superius). Het is eveneens opmerkelijk dat op dit kleine orgel naast een konventionele doublette twee voet een quart-nazard ( = fluit twee voet) aanwezig was.

Deze enkele bijzonderheden in de samenstelling van het

16. Kerkarchief Sint-Antonius, Bundel nr. 121. Dit gebeurde vóór 30 mei 1763; immers bij de overeenkomst van 30 mei 1763 om in zee te steken tot bekostigen van een nieuw plafond staat «tot stellen van welcken orghel de neiringhe heeft in zee ghegaen...».

17. R.A.B., Oud archief Blankenberge, nr. 17, fol. 339v en vlg.

18. J. Marichal is medepastoor op de parochie Sint-Amand te Uitkerke. We leerden E.H. Marichal kennen als iemand die zich ten zeerste interesseert voor alles wat met orgels verband houdt. Deze beschouwingen over het orgel danken we aan hem. 
orgel wijzen er, volgens J. Marichal, op dat de veel geliefde «galante» muziek van de toenmalige barok- en rococokomponisten op dit orgel tot klinken kon gebracht worden. In heel veel van zijn «Versetten op de oude kerktonaarden» schreef de Vlaming Abraham van den Kerckhoven voor dat de melodie zou voorgedragen worden «met den cornet». In diezelfde versetten wordt ook herhaaldelijk melding gemaakt van een echo. Zo was het eveneens de regel in de «Voluntaries» die de Engelsen John Stanley (1715-1786), William Boyce (1710-1779), zijn tijdgenoot William Walond en anderen componeerden.

Van hun kant schreven de Fransen François Couperin, de Grigny, Clérembault en anderen bovenaan hun muziek «duo sur les flûtes» en «dialogue sur les jeux d'anches». Met «flûtes» bedoelden zij de gehele fluitenfamilie in acht, vier en twee voet. Vandaar de noodzaak van een quartnazard. Het spelen op de «jeux d'anches», de tongspelen, veronderstelde dat naast de trompet altijd de clairon vier voet getrokken werd, zowel in de bas als in de diskant. In het huidig orgel van de Sint-Antoniuskerk is geen pijpwerk meer aanwezig van A.J. Berger, wel bestaat nog een gedeelte van de oorspronkelijke orgellkast en het gebeeldhouwd front.

Op 25 mei 1764 keurden de orgelisten Leimans en Dubruille, op verzoek van het Blankenbergs magistraat, het werk van Berger goed waarop het orgel definitief werd overgenomen ${ }^{19}$.

Andere opschikkingswerken volgden: Gillis Serneels herstelde in 1762 het plafond van de middenbeuk ${ }^{20}$.

Was er geen geld in kas voor de restauratie van de zijbeuken of oordeelde men dat die het minder van doen had. den ? Deken en eed van de vissersnering, die sedert kort hun zitsel in de Sint-Antoniusbeuk hadden, dachten er anders over! In een "expresse vergaederinghe» van 30 mei 1763 beslisten ze dat hun suppoosten andermaal ter visvangst zouden uitvaren en dit «voor carithate deser kercke tot plaffonneren den Sinte Anthoniuschoor" 21. Daarvoor zouden ze op 12 september in zee steken en indien nodig een tweede maal op 26 september, zo alle suppoosten erme-

19. R.A.B., Oud archief Blankenberge, nr. 17, fol. $344 v$.

20. Ibidem, Aanwinsten nr. 2581, fol. $93-93 \mathrm{v}$.

21. Kerkarchief Sint-Antonius, Bundel nr. 121. 
de akkoord gingen. Het eventueel tekort zou dan nog bijgepast worden uit de stadskas en uit deze van de nering. Averij aan netten en materiaal, opgelopen tijdens deze karitatieve vangsten, moest echter schadeloos gesteld worden met penningen uit de verkoop van de vis ${ }^{22}$.

In tegenstelling met de «jonste» tot financiering van het orgel, stelden deken en eed nu een paar voorwaarden. Vooreerst «sal er moeten in hetselve plaffon ghestelt worden eene schuijte op forme ghelick de vischschuijten alhier sijn ghemaeckt, welcke schuijte sal moeten ghemaeckt worden door eenen beeldtsnijder op schrinwerck haudt ofte andere dat daertoe succideert, welcke schuijte sal moeten ghestelt worden in het selve plaffon, reght over het visschers sitsel...» ${ }^{23}$. Inderdaad prijkt ter herinnering aan die gift in het plafond boven het visserszitsel in bas-reliëf een typische Blankenbergse schuit.

In tegenstelling met de vissersvaartuigen van Oostende en De Panne was de Blankenbergse schuit een platboomd vaartuig ( = zonder kiel) met zwaarden: dit zijn trapeziumvormige borden, aan weerszijden van de schuit bevestigd, om het omslaan en het afdrijven bij het bij-de-wind zeilen te voorkomen. Het was om op het vlakke strand te kunnen landen dat de Blankenbergse vissers dergelijke vaartuigen gebruikten zodat sinds de aanleg van een haven (1865) die platboomde schuiten geleidelijk aan vervangen werden door kielschepen. Kielschepen liggen vaster op het water, drijven bij het zeilen minder dwars af, dringen beter in de wind en zijn gemakkelijker hanteerbaar.

Een ander typerend element voor de Blankenbergse schuit en eveneens duidelijk op het bas-reliëf te zien, zijn de masten. $\mathrm{Zij}$ voert een grote mast in het midden en een fokkemast volledig vooraan op de voorsteven. De Oostendse sloepen daarentegen voerden ofwel één grote mast ofwel een grote- en een bezaansmast (kleine mast achteraan) terwijl de Panneschuiten met drie masten waren uitgerust: fokkemast vooraan, grote mast en druilmast ${ }^{24}$.

Centraal heeft men het jaartal 1763 aangebracht als herinneringsdatum aan het mooie gebaar en de milde schenking der vissers voor het vernieuwen van het plafond.

Tegenover de schuit, aan de andere zijde, bevindt zich

22. R.A.B., Oud archief Blankenberge, nt. 17, fol. 319-319v.

23. Kerkarchief Sint-Antonius, Bundel nr. 121. 
een eigenaardig teken. In voornoemde overeenkomst tussen deken en eed van de vissersnering en het stadsmagistraat wordt daar niet de minste allusie op gemaakt. Dat dit teken iets met de visserij te maken heeft, staat buiten twijfel: zeven armen met weerhaken en daaronder twee kabeljauwen! Misschien was dit het embleem van de Blankenbergse vissersnering waarbij de zeven armen de zeven leden van het bestuur der nering symboliseren, $\mathrm{nl}$. «eenen deken ende ses sorgers» ${ }^{25}$ en de twee kabeljauwen duidelijk op de visvangst wijzen.

De tweede voorwaarde die deken en eed stelden, was «dat als wanneer den orghel, tot stellen van welcken orghel de neiringhe heeft in zee ghegaen, sal wesen voltrocken, souden believen toe te staen aen hun deken ende eedt dat van soo saen dito orghel sal beginnen te spelen, den orghelist sal verobligiert wesen te spelen gratis ende onvergelt alle de missen ende loven de ghonne jaerelickx worden ghedaen ter intentie deser neiringhe...» ${ }^{26}$. Hoewel daaraan voldaan werd, meende men het toch noodzakelijk dit gratis spelen konkreter op punt te stellen, vermits pastoor en magistraat van oordeel waren dat «...die missen op sekeren nombre, ghelick sij nu ghewoon zijn te doen, bepaelt worden, op dat sij dit niet te verre extenderen en souden...» ${ }^{27}$. $\mathrm{Na}$ overleg met de bisschop van Brugge beslisten burgemeesters en schepenen op 22 oktober 1764 dat het orgel «sonder eenigh vergelt, van den kant vande voorseijde visscherije sal mooghen ghebruijckt ende ghespeelt worden in hunne jaerelickxsche ghewoonelicke diensten, te weten in veerthien missen ende twaelf loven t' sjaers...» ${ }^{28}$.

Zo kunnen we voor wat het resultaat van het herstellingswerk betreft, best verwijzen naar het inspektieverslag ${ }^{29}$ over de Sint-Antoniuskerk van het jaar 1771: «De ecclesia ... omnia bono ordine inventa sunt...»!

R. BOTERBERGE

24. F. Bly, Onze Zeilvischsloepen, Antwerpen, 1920.

25. Reglement van 1696. R.A.B., Oud archief Blankenberge, nr. 11 bis, fol. 45 . Het vernieuwd reglement van 1767 breidde de eed uit tot «eenen deken, eenen gouverneur ende ses sorgers», ibidem, nr. 18 , fol. $43 \mathrm{v}$. Zie eveneens A. Wouters, Over de oude vrije visschersnering van Blankenberge, z.d.

26. Kerkarchief Sint-Antonius, Bundel nr. 121.

27. R.A.B., Oud archief Blankenberge, nr. 17 , fol. $349 \mathrm{v}$ en vlg.

28. Kerkarchief Sint-Antonius, Bundel nr. 121.

29. R.A.B., Nieuw kerkarchief, nr. 401. 